\title{
Front Matter: Volume 9391
}

, "Front Matter: Volume 9391," Proc. SPIE 9391, Stereoscopic Displays and Applications XXVI, 939101 (10 April 2015); doi: 10.1117/12.2193659

SPIE Event: SPIE/IS\&T Electronic Imaging, 2015, San Francisco, California, United SPIE. States 


\title{
Stereoscopic Displays and Applic ations XXVI
}

\author{
Nicolas S. Holliman \\ Andrew J . Woods \\ Gregg E Favalora \\ Takashi Kawai \\ Editors
}

\section{9-11 February 2015 \\ San Franc isc o, Califomia, United States}

\section{Sponsored by}

IS\&T-The Society for Imaging Science and Technology

SPIE

Published by

SPIE 
The papers included in this volume were part of the technical conference cited on the cover and title page. Papers were selected and subject to review by the editors and conference program committee. Some conference presentations may not be available for publication. The papers published in these proceedings reflect the work and thoughts of the authors and are published herein as submitted. The publishers are not responsible for the validity of the information or for any outcomes resulting from reliance thereon.

Please use the following format to cite material from this book:

Author(s), "Title of Paper," in Stereoscopic Displays and Applications XXVI, edited by Nicolas S. Holliman, Andrew J. Woods, Gregg E. Favalora, Takashi Kawai, Proceedings of SPIE-IS\&T Electronic Imaging, SPIE Vol. 9391, Article CID Number (2015)

ISSN: 0277-786X

ISBN: 9781628414813

Copublished by

SPIE

P.O. Box 10, Bellingham, Washington 98227-0010 USA

Telephone +1 3606763290 (Pacific Time) · Fax +1 3606471445

SPIE.org

and

IS\&T-The Society for Imaging Science and Technology

7003 Kilworth Lane, Springfield, Virginia, 22151 USA

Telephone +1 7036429090 (Eastern Time) · Fax +1 7036429094

imaging.org

Copyright (C 2015, Society of Photo-Optical Instrumentation Engineers and The Society for Imaging Science and Technology.

Copying of material in this book for internal or personal use, or for the internal or personal use of specific clients, beyond the fair use provisions granted by the U.S. Copyright Law is authorized by the publishers subject to payment of copying fees. The Transactional Reporting Service base fee for this volume is $\$ 18.00$ per article (or portion thereof), which should be paid directly to the Copyright Clearance Center (CCC), 222 Rosewood Drive, Danvers, MA 01923. Payment may also be made electronically through CCC Online at copyright.com. Other copying for republication, resale, advertising or promotion, or any form of systematic or multiple reproduction of any material in this book is prohibited except with permission in writing from the publisher. The CCC fee code is 0277-786X/15/\$18.00.

Printed in the United States of America.

Paper Numbering: Proceedings of SPIE follow an e-First publication model, with papers published first online and then in print. Papers are published as they are submitted and meet publication criteria. A unique citation identifier (CID) number is assigned to each article at the time of the first publication. Utilization of CIDs allows articles to be fully citable as soon as they are published online, and connects the same identifier to all online, print, and electronic versions of the publication. SPIE uses a six-digit CID article numbering system in which:

- The first four digits correspond to the SPIE volume number.

- The last two digits indicate publication order within the volume using a Base 36 numbering

system employing both numerals and letters. These two-number sets start with 00, 01, 02, 03, 04, $05,06,07,08,09,0 A, 0 B \ldots 0 Z$, followed by 10-1Z, 20-2Z, etc.

The CID Number appears on each page of the manuscript. The complete citation is used on the first page, and an abbreviated version on subsequent pages. 


\title{
Contents
}

\author{
vii Authors \\ ix Conference Committee \\ xi Introduction
}

SESSION 1 HIGH PARALLAX DISPLAYS

939102 Enhancement of the effective viewing window for holographic display with amplitude-only SLM [9391-1]

939103 A full-parallax 3D display with restricted viewing zone tracking viewer's eye [9391-2]

\section{SESSION 2 CAMERA DESIGNS}

939105 3D UHDTV contents production with 2/3-inch sensor cameras [9391-3]

939106 Integral three-dimensional capture system with enhanced viewing angle by using camera array [9391-4]

939107 A stereoscopic lens for digital cinema cameras [9391-5]

939108 A novel optical design for light field acquisition using camera array [9391-6]

939109 Real-time viewpoint image synthesis using strips of multi-camera images [9391-7]

\section{SESSION 3 APPLICATIONS}

$93910 \mathrm{~A}$ Interactive stereo games to improve vision in children with amblyopia using dichoptic stimulation [9391-8]

9391 OC Visual perception and stereoscopic imaging: an artist's perspective [9391-10]

9391 OD Assessing the benefits of stereoscopic displays to visual search: methodology and initial findings [9391-11]

\section{SESSION 4 LIGHT FIELD DISPLAYS}

9391 OE Small form factor full parallax tiled light field display [9391-12]

9391 OF Load-balancing multi-LCD light field display [9391-13] 
93910 L Light field display simulation for light field quality assessment [9391-14]

$9391 \mathrm{OH}$ Integration of real-time 3D capture, reconstruction, and light-field display [9391-15]

\section{SESSION 5 AUTOSTEREOSCOPIC DISPLAYS}

9391 0J A large 1D retroreflective autostereoscopic display [9391-16]

9391 OL Dual side transparent OLED 3D display using Gabor super-lens [9391-18]

$93910 \mathrm{M}$ 360-degree three-dimensional flat panel display using holographic optical elements [9391-19]

\section{KEYNOTE SESSION}

9391 ON What is stereoscopic vision good for? (Keynote Paper) [9391-49]

SESSION 6 HUMAN FACTORS AND PERFORMANCE

939100 Subjective contrast sensitivity function assessment in stereoscopic viewing of Gabor patches [9391-20]

9391 OP An objective method for 3D quality prediction using visual annoyance and acceptability level [9391-21]

$93910 Q \quad$ Disparity modification in stereoscopic images for emotional enhancement [9391-22]

9391 OR Preference for motion and depth in 3D film [9391-23]

\section{SESSION 7 VISUAL COMFORT STUDIES}

9391 OT Effects of blurring and vertical misalignment on visual fatigue of stereoscopic displays [9391-25]

9391 OU Subjective and objective evaluation of visual fatigue on viewing 3D display continuously [9391-26]

9391 OV Study of objective evaluation indicators of 3D visual fatigue based on RDS related tasks [9391-27]

\section{SESSION $8 \quad$ IMAGE PROCESSING}

$93910 X \quad$ Multi-view stereo image synthesis using binocular symmetry-based global optimization [9391-28]

9391 OY Depth assisted compression of full parallax light fields [9391-29]

iv 
$93910 Z$ A 3D mosaic algorithm using disparity map [9391-30]

939111 Data conversion from multi-view cameras to layered light field display for aliasing-free 3D visualization [9391-42]

SESSION 9 MULTI-VIEW AND INTEGRAL IMAGING DISPLAYS

939112 A new type of multiview display [9391-32]

939113 Compact multi-projection 3D display using a wedge prism [9391-33]

939114 Integral 3D display using multiple LCDs [9391-34]

939115 A super multi-view display with small viewing zone tracking using directional backlight [9391-35]

\section{SESSION 10 IMAGE PRODUCTION AND PERCEPTION}

939116 Real object-based 360-degree integral-floating display using multiple depth camera [9391-36]

939117 Multi-layer 3D imaging using a few viewpoint images and depth map [9391-37]

939118 Evaluation of vision training using 3D play game [9391-38]

939119 Partially converted stereoscopic images and the effects on visual attention and memory [9391-39]

\section{INTERACTIVE PAPER SESSION}

9391 1A Enhancement of viewing angle with homogenized brightness for autostereoscopic display with lens-based directional backlight [9391-40]

9391 1B Effect of Petzval curvature on integral imaging display [9391-41]

9391 1C Free-viewpoint video synthesis from mixed resolution multi-view images and low resolution depth maps [9391-43]

9391 ID Formalizing the potential of stereoscopic 3D user experience in interactive entertainment [9391-44]

9391 1G Usability of stereoscopic view in teleoperation [9391-47]

939111 Dynamic mapping for multiview autostereoscopic displays [9391-51] 
Proc. of SPIE-IS\&T Vol. $9391939101-6$

\section{Downloaded From: https://www.spiedigitallibrary.org/conference-proceedings-of-spie on 26 Apr 2023
Terms of Use: https://www.spiedigitallibrary.org/terms-of-use}




\section{Authors}

Numbers in the index correspond to the last two digits of the six-digit citation identifier (CID) article numbering system used in Proceedings of SPIE. The first four digits reflect the volume number. Base 36 numbering is employed for the last two digits and indicates the order of articles within the volume. Numbers start with 00, 01, 02, 03, 04, 05, 06, 07, 08, 09, 0A, 0B...0Z, followed by 10-1Z, 20-2Z, etc.

\author{
Allison, Robert S., OR \\ Alpaslan, Zahir Y., OE, OG, OY \\ An, Jungkwuen, 02 \\ Arai, Jun, 06, 14 \\ Ash, Isabel M., OA \\ Atsuta, Daiki, $0 Q$ \\ Baasantseren, Ganbat, 1B \\ Baek, Sangwook, OT \\ Batbayr, Densmaa, 1B \\ Beppu, Naoto, 03 \\ Boonsuk, Wutthigrai, $1 \mathrm{G}$ \\ Cao, Xuan, 08, OF \\ Cave, Kyle R., OD \\ Cheng, Dewen, OV \\ Cho, Sung-Woo, OL \\ Choi, Chil-Sung, 02 \\ Choimaa, Lodoiravsal, 1B \\ Chung, U-in, 02 \\ Cobb, Sue V., OA \\ Dashdavaa, Erkhembaatar, 16 \\ Date, Munekazu, 09 \\ Davis, James, 11 \\ de la Barré, René, 12 \\ Donnelly, Nicholas, OD \\ Eastgate, Richard M., OA \\ El-Ghoroury, Hussein S., OE, OG, OY \\ Emori, Takaaki, 1C \\ Erdenebat, Munkh-Uchral, 16 \\ Fakis, Apostolos, OA \\ Foss, Alexander J. E., OA \\ Fournier, Jérôme, OP \\ Fujii, Toshiaki, 11, 1C \\ Geng, Zheng, 08, OF, OH \\ Godwin, Hayward J., OD \\ Graziosi, Danillo B., OY \\ Gregson, Richard M., OA \\ Guo, Anxiang, OU \\ Haar, Jérémy, 00 \\ Häkkinen, Jukka, $O Q$ \\ Hamacher, Alaric, 05 \\ Hartle, Brittney, OR \\ Hepburn, Trish, OA \\ Herbison, Nicola, OA \\ Holliman, Nick S., OD \\ Huang, Yi, OV \\ Jung, Yong Ju, OX \\ Jurk, Silvio, 12 \\ Kakeya, Hideki, 0Z, IA \\ Kawai, Takashi, OQ, 19
}

Kazimi, Ali, OR

Khaustova, Darya, OP

Kim, Dae-Sik, OL

Kim, Hak Gu, OX

Kim, Hojung, 02

Kim, Jung-Ho, 18

Kim, Nam, 16

Kim, Sanghyun, 0 Q, 19

Kim, Sang-II, 05

Kim, Sunil, 02

Kim, Young-Seok, 16

Kimpe, Tom R., 00

Kojima, Akira, 09

Kuhlmey, Mathias, 12

Kwon, Ki-Chul, 16

Kwon, Soon-Chul, 18

Lee, Byoungho, 13

Lee, Chang-Kun, 13

Lee, Chulhee, 0T

Lee, Hong-Seok, 02

Lee, Seung-Hyun, 05, 18

Le Meur, Olivier, OP

$\mathrm{Li}$, Tuotuo, $\mathrm{OH}$

Lipton, Lenny, 07

Liu, Jing, 11

Liu, Yongchun, $\mathrm{OH}$

Liu, Yue, OV

Liversedge, Simon P., OD

LU, Yang, OU

Lugtigheid, Arthur, OR

MacKeith, Daisy, OA

Malzbender, Tom, 1 I

Mason, Steve, OC

Masuch, Maic, ID

Matsubara, Rie, OG

Menneer, Tamaryn, OD

Mishina, Tomoyuki, 06, 14

Mitsuya, Reiko, 19

Miura, Masato, 06, 14

Miyazaki, Jin, 15

Morikawa, Hiroyuki, 19

Mukai, T., 1A

Okaichi, Naoto, 06, 14

Pardeshi, Sunil, 05

Park, Soon-gi, 13

Pei, Renjing, $\mathrm{OH}$

Philips, Wilfried, 00

Piepers, Bastian, 00

Platiša, Ljiljana, 00 
Purdy, Jonathan H., OA

Qin, Siyang, 11

Ranieri, Nicola, OJ

Read, Jenny C. A., ON

Ro, Yong Man, OX

Rousson, Johanna, 00

Rupkalvis, John, 07

Saito, Toyohiro, 11

Sakamoto, Hirotaka, 17

Schild, Jonas, 1D

Seo, Juwon, 02

Seo, Wontaek, 02

Shestak, Sergey, OL

Smithwick, Quinn Y. J., OJ

Son, Kwang-Chul, 18

Song, Hoon, 02

Suginohara, Hidetsugu, 17

Sung, Geeyoung, 02

Suyama, Shiro, 17

Takada, Hideaki, 09

Takahashi, Hideya, OM

Takahashi, Keita, 11, 1C

Takeuchi, Yusuke, OM

Tehrani, Mehrdad Panahpour, 11, 1C

Vivian, Anthony, OA

Wang, Danli, OU

Wang, Yongtian, OV

Watanabe, Katsumi, 19

Whangboo, Taeg-Keun, 05

Wilcox, Laurie M., OR

Wu, Che-An, 11

Wu, Hui-Ying, 16

Wyckens, Emmanuel, OP

Xie, Yaohua, OU

Yabu, Hirofumi, OM

Yamada, Kenji, OM

Yamamoto, Hirotsugu, 17

Yamanaka, Satoshi, 17

Yang, Xinpan, OU

Yendo, Tomohiro, 03, 15

Yoo, Kwan-Hee, 16

Yoon, Soo Sung, OX

Yoshimoto, Kayo, OM

Yu, BO, OZ

Zhang, Bipeng, 11

Zhang, Mei, 08, OF

Zhang, Xiao, OF, OH

Zhang, Zhaoxing, $08, \mathrm{OH}$

Zou, Bochao, OV 


\section{Conference Committee}

Symposium Chair

Sheila S. Hemami, Northeastern University (United States)

Symposium Co-chair

Choon-Woo Kim, Inha University (Korea, Republic of)

Conference Chairs

Nicolas S. Holliman, The University of York (United Kingdom)

Andrew J. Woods, Curtin University (Australia)

Gregg E. Favalora, VisionScope Technologies LLC (United States)

Takashi Kawai, Waseda University (Japan)

Conference Program Committee

Neil A. Dodgson, University of Cambridge (United Kingdom)

Davide Gadia, Università degli Studi di Milano (Italy)

Hideki Kakeya, University of Tsukuba (Japan)

John D. Stern, Intuitive Surgical, Inc. (Retired) (United States)

Vivian K. Walworth, StereoJet, Inc. (United States)

Chris Ward, Lightspeed Design, Inc. (United States)

Michael A. Weissman, Perspective Systems (United States)

Samuel Zhou, IMAX Corporation (Canada)

Session Chairs

High Parallax Displays

Nicolas S. Holliman, The University of York (United Kingdom)

Keynote Session I

Nicolas S. Holliman, The University of York (United Kingdom)

Camera Designs

Nicolas S. Holliman, The University of York (United Kingdom)

Applications

Takashi Kawai, Waseda University (Japan)

Light Field Displays

Hideki Kakeya, University of Tsukuba (Japan) 
Autostereoscopic Displays

Hideki Kakeya, University of Tsukuba (Japan)

Keynote Session II

Nicolas S. Holliman, The University of York (United Kingdom)

Human Factors and Performance

John O. Merritt, The Merritt Group (United States)

Visual Comfort Studies

Takashi Kawai, Waseda University (Japan)

Image Processing

Davide Gadia, Università degli Studi di Milano (Italy)

Multi-View and Integral Imaging Displays

Nicolas S. Holliman, The University of York (United Kingdom)

Image Production and Perception

Davide Gadia, Università degli Studi di Milano (Italy)

SD\&A Closing Remarks and Prizes

Nicolas S. Holliman, The University of York (United Kingdom) 


\section{Stereoscopic Displays and Applications XXVI}

\section{The World's Premier Conference for 3D Innovation}

\section{Introduction}

The 2015 Stereoscopic Displays and Applications (SD\&A) conference was the twenty-sixth in the series, moving into the second quarter-century where the conference has developed into the premier venue for the dissemination of research on stereoscopic displays and their applications.

SD\&A attracts key players in the field: stereoscopic experts from industry and academia presented the two keynotes, participated on the discussion panel, and spoke in the technical presentations. The conference had an excellent technical program covering a wide range of stereoscopic topics.

This year the conference received 74 paper submissions. Of these, 36 were accepted for oral presentation (49\%), with an additional 6 interactive papers accepted as posters.

This conference proceedings volume contains the technical papers in support of both the presentations and posters given at the conference. This introduction gives an overview of the conference-a reminder for those who attended and an insight into what happened for those who were unable to attend.

SD\&A took place 9-11 February 2015 as part of the 2015 IS\&T/SPIE Electronic Imaging: Science and Technology Symposium, at the Hilton San Francisco Union Square Hotel, in downtown San Francisco.

The first day had four technical sessions running in the symposium plenary auditorium. Topics covered high parallax displays, camera designs, applications and light field displays. The day also included the first of the two keynotes, the two-hour 3D theatre, and the twenty-sixth SD\&A conference banquet.

The first keynote presentation was given by lan Bickerstaff from Sony Computer Entertainment (United Kingdom) it was entitled A Stereoscope for the Playstation Generation. Ian discussed in depth his thoughts on VR displays: "After many years of waiting, virtual reality will soon be available for home use. Smart phones have 
given us small, high quality displays and accurate movement tracking while the games industry has given us the necessary real-time graphics power to drive these displays. In addition, advances in technologies such as free-form optics, and binaural audio processing have arrived at just the right time."

More than just viewing images on a screen, the aim of ventures such as Sony Computer Entertainment's Project Morpheus is to produce a system that convinces the wearer that they have been transported to another place, and the display system is a vital component. Ever since the beginning of photography, equipment has been created to achieve this goal: an 1850s Brewster stereoscope contains many design features found in the latest HMDs. In both, near orthostereoscopic viewing conditions ensure that subjects appear life sized and with realistic depth placement. Unlike a monitor or cinema screen, images are always seen from an optimum viewing position with keystone distortion and vertical parallax kept to a minimum. A far greater range of depth can be viewed comfortably on a head-mounted display than is possible on a conventional screen."

The two-hour 3D Theatre Session is a regular highlight event that showcases 3D content from around the world. This year, the following forty-one pieces (or segments thereof) were screened:

1. "The Whitewashing of 5 Pointz" - Ben Schwartz (USA) $†$

2. "Luigi's Pizzaride 3D" - Florian Werzinski (Germany) †

3. "Safety Geeks SVI trailer" - Lumen Actus Productions (USA) †

4. "Geometry of Numbers" - San Base (Canada); music by Ugo Altamore (Italy) $\dagger$

5. "Mr Hublot" - Laurent Witz \& Alexandre Espigares (Luxembourg) †

6. "Hyperlapse - Scenic in Japan \# 1" - Takashi Sekitani (Japan) †

7. "Gravitational Lensing" - Ralf Kaehler (KIPAC/SLAC), Carter Emmart (AMNH), Tom Abel (KIPAC/SLAC) (USA) †

8. "Intermission" (from 2003) - Don Hertzfeldt and Robert Howell (USA) †

9. "Airground" - Sylvia Nicolaides (Cyprus) †

10. "Elysian Fields" - Ina Conradi Chavez (Singapore) †

11. "Maidan Today" - Stéphane Dalmat (France) †

12. "Temple of Zen 3D" - Tsz Shan Monastery (Hong Kong) †

13. "Dzignlight Studios Timelapse 2015" - Eric Deren (USA) †

14. "Cosplay Dreams 3D" - Passage Productions and Drama House Productions (USA) $\dagger$

15. "Maleficent" - Walt Disney Pictures (USA)

16. "Austin, Texas 3D Time Lapse" - Landon Gaus (USA)

17. "Fanfare Intro Foxtrot" - Chris Casady (USA)

18. "Being there; Mauritshuis The Hague - Vermeer - Girl with a Pearl Earring" René van Gageldonk (Netherlands) 
19. "Frozen" - Walt Disney Animation Studios (USA)

20. "Austin Surhoff, UT Swimmer" - Patricio Elizondo (USA)

21. "Ratatouille" - Pixar Animation Studios (USA)

22. "Cochemare" - Chris Lavis and Maciek Szczerbowski (Canada) †

23. "The Depths" - Jordan Dowler-Coltman (Writer/Director) (Canada) †

24. "My Robot" - PARAN52FILM (CEO: Choi Yang Hyun) (South Korea) †

25. "Northern Lights over Mount Halde" - Morten Skallerud (Norway) †

26. "The 3D-Machine - the series - Episode 3" - Ka-Ching Cartoons (Netherlands) †

27. "Frames" - Emmanuel Albano (Canada) $\dagger$

28. "Snakes 3D" - Wild Earth Media (South Africa) †

29. "Compromiso: ALA 15 (Commitment: 15th Wing)" - Alfredo Gonzalez / Sergio de Uña / José Luis Roig (Spain) †

30. "Grami's Circus Show" - Studio Gale Co, Ltd. / KBS Media (Korea) †

31. "Red White Black and Blue" - Nicholas D'Agostino (USA) †

32. "Trail Riders of America Double Cross and Dirt Jump Contest" - Nat Bartholomew (USA) $\dagger$

33. "The Chaperone 3D" - Fraser Munden (Canada) $\dagger$

34. "Yili" - Digital Magic Limited (China) †

35. "One Night in Hell" - Jason Jameson \& James Hall (England) $\dagger$

36. "The Bubble" (from 1966) - 3-D Film Archive, LLC (USA)

37. "Pequeñas Voces (Little Voices) trailer" - Jairo Carrillo (Colombia)

38. "Later, in the Restaurant..." - Karel Bata (England)

39. "Friskies 3D" - Brash 3D (Colombia)

40. "Dragonfly Squadron" (from 1954) - 3-D Film Archive, LLC (USA)

41. "Oceans" - Maria Juranic (USA)

All entries were screened in high-quality polarized 3D on the conference's large projection screen. The Best of Show awards were judged by Eric Kurland (3-D SPACE) and Lenny Lipton (Leonardo IP). Content contributors self-selected if they wished their entry to be included in the competition - indicated by $(\dagger)$ in the list above.

The judges chose the following 3D content winners as Best of Show:

Live Action - "The Whitewashing of 5 Pointz", B. Schwartz (USA)

Computer Generated - "Cochemare", C. Lavis \& M. Szczerbowski (Canada)

The producers of the 2015 SD\&A 3D Theater were John Stern (Intuitive Surgical Inc., retired), Chris Ward (Lightspeed Design, USA), and Andrew Woods (Curtin University, Australia). Additional support was provided by Dan Lawrence 
(Lightspeed Design). The 3D content partners for the 3D Theater session were the LA 3-D Movie Festival (USA), 3D Content Hub (Germany and Australia), and 3-D Film Archive (USA).

The evening concluded with the twenty-sixth anniversary conference dinner at The Old Siam Thai Restaurant on Ellis and Mason, opposite the conference hotel.

The second day of the conference had three technical sessions on autostereoscopic displays, human factors and performance and visual comfort. The day also included the second SD\&A keynote, the demonstration session, and the poster session. Full papers from both the technical sessions and the poster session are contained in this volume.

The second keynote presentation was presented by Jenny Read, Reader in Vision Science in the Institute of Neuroscience at Newcastle University. She gave an informative and illuminating presentation on the theme "What is stereoscopic vision good for?" covering topics in stereo vision in humans, animals, and insects, and a recently started project investigating stereo testing for children using a gaming system.

The final event of the day was the ever-popular Demonstration Session, which has run every year since 1990. Since 2006, this has been a symposium-wide event, open to demonstrators from all of the Electronic Imaging conferences. It was pleasing to see a wide range of demonstrations and to see a large audience actively engaging with the various displays and vendors. The buzz in the demonstration session was excellent.

A prize was awarded for the best 3D demonstration at the session. The judging panel consisted of the on-site conference chairs and the winner was Steve Mason, Yavapi College (USA), for his demonstration of electronic and hardcopy stereoscopic artworks produced using the ChromaDepth technique.

The third day of the SD\&A conference had the popular discussion forum and three technical sessions on image processing, multi-view and integral imaging displays, and image production and perception. The day concluded with the Electronic Imaging symposium reception.

The discussion forum considered VR and 3D: Is good 3D necessary for good VR. The panel comprised moderator Lenny Lipton (Leonardo IP), lan Bickerstaff (Sony Computer Entertainment), Margret Dolinsky (Indiana University), and Gordon Wetzstein (Stanford University).

Video recording was made of most technical sessions in the main SD\&A conference hall including the two keynote presentations. Editing is underway and the content will be available online via the SD\&A conference website. 
In addition to the prizes for the theatre and demonstrations, a final prize was offered at the conference for the best use of the stereoscopic projection tools during the presentations. The winner, chosen by the SD\&A conference chairs, was:

[9391-50] "A Stereoscope for the Palystation Generation", Ian Bickerstaff, Sony Computer Entertainment (United Kingdom)

The prizes this year were copies of Stereoscopic Displays and Applications 19902009: A Complete 20-Year Retrospective and The Engineering Reality of Virtual Reality 1994-2009 (Special Collection) (DVD-ROM) (ISBN 9780819476593), published by SPIE in 2010 . The prizes were kindly donated by SPIE Press.

Congratulations to all our prize-winners in the 3D Theatre, demonstration session, and technical presentation categories.

Many individuals and companies contributed in various ways to the success of this year's SD\&A conference:

- We appreciate the support of this year's stereoscopic projection sponsors: DepthQ (USA), Christie Digital (USA) and Tekamaki (USA). The ability to present high-quality large-screen stereoscopic images and video at the conference is vital to the success of the conference. Many thanks to the individuals who worked tirelessly on-site: Chris Ward from Lightspeed Design; Dan Lawrence from Lightspeed Design, and Adrian Romero and staff from Spectrum Audio Visual. The AV setup was overseen by Stephan R. Keith; Diana Gonzalez from IS\&T; and Andrew Woods.

- We very much appreciate the dedicated support of Stephan R. Keith (SRK Graphics Research), who had a multi-tasked role at this conference, including supporting the needs of all of our presenters.

- We are grateful to all of the providers of 3D content for allowing their content to be shown to the conference audience at the 3D Theatre Session.

- Thanks to the demonstration session presenters for bringing equipment to show - especially to the presenters who brought equipment from overseas.

- The conference committee plays an important role throughout the year, ensuring the correct technical direction of the meeting. Sincere thanks go to our founding chair, John Merritt, and our committee, Neil Dodgson, Davide Gadia, Hideki Kakeya, John Stern, Vivian Walworth, Chris Ward, Michael Weissman, and Samuel Zhou.

- We particularly wish to acknowledge and thank Vivian Walworth and Samuel Zhou, who are retiring from the committee following the 2015 conference. They have both provided many years of valued service to the conference.

- Thanks also to the staff at IS\&T and SPIE, the two organizing societies, who were instrumental in organizing all manner of aspects of the meeting. 
- Most importantly, we thank the conference authors and attendees, who ultimately made this meeting such a successful event. Thanks especially to those who travel a long way to join us each year.

Conference activities do not stop at the end of the annual meeting. The SD\&A conference website and Linkedln group provide a focus for conference activities during the time between conferences. We will soon be actively seeking abstracts for the 2016 conference, with a deadline in mid-2015 - see the website for details and deadlines. You can join the SD\&A Linkedln group to receive conference announcements. The website has an extensive collection of photographs highlighting the activities of past conferences. In addition the website hosts the stereoscopic virtual library, which contains several historically important books that have been digitized, in full, into PDF format, and are available for free download. The SD\&A conference runs an active Linkedln group which is available at:

\section{www.linkedin.com/groups?gid $=1945944$}

You can visit the conference website to gain an understanding of the past, present, and future of stereoscopic imaging. Please think now about submitting a paper or attending next year's conference. The Stereoscopic Displays and Applications conference website is at:

\section{www.stereoscopic.org}

Next year, the 27th annual SD\&A conference will be held in February 2016, at the Hilton San Francisco Union Square Hotel in downtown San Francisco.

The 2016 SD\&A conference will continue a tradition of presenting and demonstrating the latest technologies relevant to stereoscopic displays and applications. Please consider attending, presenting, or demonstrating at the 2016 event. We hope to see you there!

\section{Nicolas S. Holliman \\ Andrew J. Woods \\ Gregg E. Favalora Takashi Kawai}




\section{Stereoscopic Displays and Applications XXVI}

The World's Premier Conference for 3D Innovation

\section{Projection Sponsors}

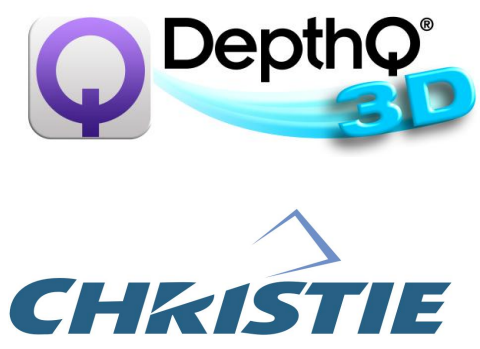

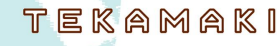

SD\&A 3D Theatre Content Partners
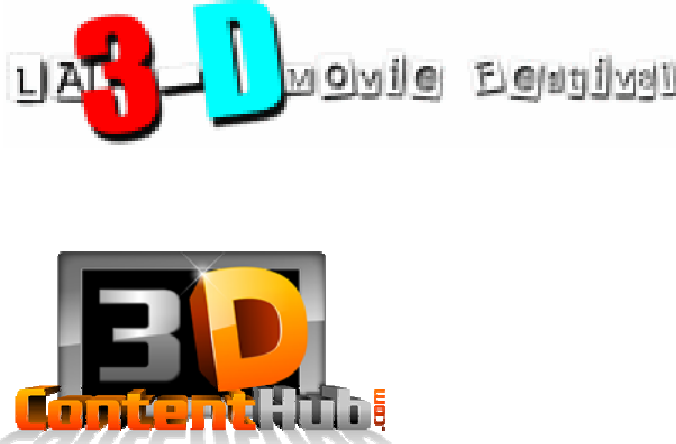

3-D FILM ARCFIIVE 
Proc. of SPIE-IS\&T Vol. $9391939101-18$

Downloaded From: https://www.spiedigitallibrary.org/conference-proceedings-of-spie on 26 Apr 2023 Terms of Use: https://www.spiedigitallibrary.org/terms-of-use 